\title{
Análise Espacial dos Riscos de Erosão e Inundação na Bacia do Rio Cuiá
}

\author{
Leonardo Pereira e Silva \\ Programa de Pós-G raduação em Engen haria U rbana e A mbiental, CT / UFPB \\ leojampa@com.br \\ Celso Augusto Guimarães Santos \\ Departamento de Engenharia Civil eAmbiental, UFPB \\ celso@ct.ufpb.br \\ Recebido: 28/05/08 -revisado: 27/02/10 -aceito: 03/08/10
}

\begin{abstract}
RESUM 0
0 presente trabalho objetiva identificar áreas sujeitas à in undação, erosão e deslizamento de terra na bacia do rio Cuiá, utilizando técnicas de geoprocessamento e modelagem hidrossedimentológica. Para a obten ção do mapa do uso ade quado do solo, foram integrados os mapas de inundação, produ ção de sedimentos, impermeabilização do solo e deslizamento de terra, obten do-se um mapa síntese das variávés en contradas no decorrer do trabalho, resultando em cinco cenários diferenciados por seus graus de risco. Foi realizado um cruzamento entres os temas, para isso utilizou-se a álgebra booleana en volven do as operações de união e de intercessão. A proposta de adequação do uso e ocu pação do solo, su gerida neste trabaIho com base nas variáveis: (a) risco à inundação e ao deslizamento, (b) grau de impermeabilização, e(c) erosão, recomenda que o cenário R5 seja designado como área de recu peração urbana, por apresentar os problemas de impermeabilização, erosão, inun dação e deslizamento; 0 cenário R 4 seja uma área de recu peração ambiental, visto que está sujeito a risco de deslizamento e alto grau de impermeabilização; 0 cenário R3 seja área de reestruturação u rbana, devido aos problemas de deslizamento, erosão e impermeabilização; o cenário R2 seja uma área de conservação ambiental, visto que existe apen as problema de deslizamento; e que finalmente o cenário R 1 seja área de ocu pação dirigida e desen volvimento econômico compatível, por não apresentar risco
\end{abstract}

Palavras-chave: M odelagem; deslizamento; geoprocessamento; bacia hidrográfica.

INTRODUÇÃO

Com os crescentes problemas de degradação e desequilíbrios ambientais ocasionados pelas intervenções humanas que afetam os elementos da paisagem natural, a água torna-se um importante recurso que juntamente com sua bacia de captação devem ser preservadas. Neste contexto, a bacia hidrográfica apresenta-se como um excelente laboratório de estudo de problemas ambientais, e como uma unidade integradora dos setores naturais e sociais, devendo ser administrada com esta função, a fim de que os impactos ambientais sejam minimizados (Cunha e Guerra, 1999). Quando sujeitas ao processo de ocupação, as bacias podem ser submetidas a diversos desequilíbrios ambientais. Segundo Cunha e Guerra (1999), as mudanças ocorridas no interior das bacias de drenagem podem ter causas naturais; entretanto, nos últimos anos, a ação hu- mana tem sido um importante agente acelerador dos processos de desequilíbrio da paisagem.

A bacia hidrográfica do rio Cuiá, localizada na parte sul do município de João Pessoa, é caracterizada como urbana, e vem sofrendo várias alterações que prejudicam os processos ambientais. Tais alterações podem ser elencadas, como: crescimento urbano desordenado e perda das características naturais dos rios ocasionada pelas sucessivas obras de engenharia, que, muitas vezes, não levam em consideração o conjunto da rede de drenagem e modificam as seções transversais e o perfil longitudinal dos rios, reduzindo, assim, a eficiência do fluxo de água, e causando mudanças nos processos hidrológicos. Áreas urbanizadas são mais susceptíveis à inundação, pois uma determinada precipitação, que antes da urbanização não causaria problemas, após a urbanização podem resultar em vazões muito maiores e inundações generalizadas, devido, principalmente, à remoção da vegetação, à impermeabilização do solo e à canalização do rio, além do 
carreamento de sedimentos, lixo e esgotos para os cursos de água (Gondim Filho et al., 2004). Este estudo se propõe a identificar, através de documentos cartográficos, as formas de ocupação e as condicionantes naturais da bacia, além de verificar as áreas que apresentam conflitos de uso e ocupação do solo que causam impactos negativos e/ ou positivos ao meio ambiente. Neste sentido, as geotecnologias, através do geoprocessamento, oferecem ferramentas capazes de propiciar meios para o levantamento de dados do meio físico, do uso e ocupação do solo, bem como, na integração destes dados para posterior análise e interpretação, os quais resultam em subsídios relevantes às propostas de ordenamento físico territorial (Valério Filho et al., 2005). Assim, as técnicas de geoprocessamento serão utilizadas neste trabalho, visto que, permitem o tratamento dos dados, desde a sua entrada, passando pela edição, armazenamento e, finalmente, as análises ambientais, com a extração das informações registradas nos mapas, por meio do uso de ferramentas SIG e de modelagem hidrossedimentológica que possibilitará a simulação de cenários e levantamento das áreas susceptíveis à inundação e ao processo erosivo.

\section{DESLIZAMENTOS}

A urbanização altera diretamente o ciclo hidrológico, interferindo no processo de infiltração da água no solo e no escoamento superficial, provocando inundações e deslizamentos (Gonçalves e Guerra, 2001). Os deslizamentos caracterizam-se como movimentos de massa do tipo rápido e correspondem à deslocamento de um grande volume da parte superficial do solo decomposto. Tal movimentação é iniciada pelo efeito da gravidade que coincide com a influência da alta pluviosidade (intensidade, duração e frequência) (Araújo et al., 2003). Os deslizamentos podem ser provocados por fatores naturais (geologia, declividade, solo, vegetação, clima, etc.) e antrópicos (uso e ocupação do solo). No entanto, entre os fatores naturais, a chuva exerce um importante papel, pois quase todos os registros estão associados a eventos de chuva de grande intensidade associadas a relevos acidentados.

Já entre os fatores antrópicos, destaca-se o uso e ocupação do solo, visto que, dependendo da cobertura do solo, este poderá estar mais ou menos susceptível aos processos erosivos. Os tipos de uso do solo contribuem decisivamente na ocorrência de deslizamentos, especialmente em áreas de aglome- rados urbanos com ocupações irregulares das encostas (Delgado et al., 2006).

\section{INUNDAÇÃO}

As enchentes e inundações urbanas também são desastres que causam relevante impacto sobre a sociedade. As enchentes, ampliadas pela urbanização em geral, ocorrem em bacias de pequeno e médio porte. Segundo Vianna (2000), as cheias são definidas como eventos em que são verificados valores extremos de vazão associados a inundações das planícies ou áreas adjacentes ao canal principal dos cursos d'água. São fenômenos naturais dos regimes dos rios e de outros corpos d'água, sendo que todo rio tem sua área natural de inundação. As inundações passam a ser um problema quando os limites naturais dos rios não são respeitados. A enchente caracteriza-se por uma vazão relativamente grande de escoamento superficial. Já a inundação, caracteriza-se pelo extravasamento do canal. Assim, uma enchente pode não causar inundação, principalmente, se obras de controle forem construídas para esse fim. Por outro lado, mesmo não havendo um grande aumento de escoamento superficial, poderá acontecer uma inundação, caso haja alguma obstrução no canal natural do rio (Villela e Mattos, 1975).

As inundações em áreas urbanas ocorrem, principalmente, devido ao desmatamento, à pavimentação do solo, às construções, aos movimentos de terra, e aos aterros de reservatórios e de curso d'água, aumentando a freqüência, magnitude das enchentes, e o volume da água do rio que transborda até o leito maior da planície de inundação, que em muitos casos chegam a atingir as habitações que estão em áreas inapropriadas à ocupação humana. Esses fatores, em conjunto, causam sérios problemas de inundação. Quando a precipitação é intensa e a água que chega ao solo não tem capacidade de infiltrar, grande parte do volume escoa para o sistema de drenagem, superando a capacidade natural de escoamento. 0 excesso do volume que não consegue ser drenado ocupa a várzea, inundando-a, de acordo com a topografia das áreas próximas aos rios. Este tipo de inundação é denominado de inundação de áreas ribeirinhas (Tucci et al., 2003). Existe outro tipo de inundação que está diretamente ligado à urbanização e pode ser dividida de acordo com os fatores que a provoca. Nas regiões ribeirinhas, as inundações ocorrem na várzea natural do rio e são provocadas devido à má ocupação, essas áreas, geralmente, pertencem ao poder público e não têm 
valor imobiliário, sendo, portanto, frequentemente invadidas por sub-habitações. Na medida em que a população impermeabiliza o solo e acelera o escoamento através de obstruções como condutos e canais, a quantidade de água que chega ao mesmo tempo no sistema de drenagem aumenta, produzindo inundações mais frequentes que as já existentes quando a superfície era permeável e o escoamento se dava pelo ravinamento natural. Este tipo de inundação é tipicamente devido à urbanização ( $E$ nomoto, 2004; Tucci et al., 2003). Uma forma de solucionar o problema de inundação é a delimitação dessas áreas, i.e., um zoneamento de áreas sujeitas à inundação. Desta forma, é possível analisar as dimensões das áreas de inundação, e, portanto, caracterizar as regiões mais favoráveis à ocupação urbana na bacia sem o perigo de inundação. A possibilidade de previsão das inundações, com antecedência apropriada, estimula ações de prevenção e respostas que podem reduzir ou eliminar perdas humanas e materiais.

\section{METODOLOGIA}

\section{Bacia hidrográfica do rio Cuiá}

A bacia do rio Cuiá está inserida no município de João Pessoa, com uma área de aproximadamente $40 \mathrm{~km}^{2}$, valores altimétricos que variam de 0 até $60 \mathrm{~m}$ e é delimitada pelas coordenadas UTM $302.000 \mathrm{E} / 9.210 .000 \mathrm{~N}$ e $292.000 \mathrm{E} / 9.200 .000 \mathrm{~N}$. Limita-se ao norte com a Bacia do Rio Jacarapé, ao sul com a Bacia do Rio Gramame, ao oeste com o conjunto $\mathrm{H}$ abitacional Ernany Sátiro e a leste com $\mathrm{O}$ O ceano Atlântico. A Figura 1 mostra a localização da bacia no Estado da Paraíba.

\section{BACIA DO RIO CUÍÁ}

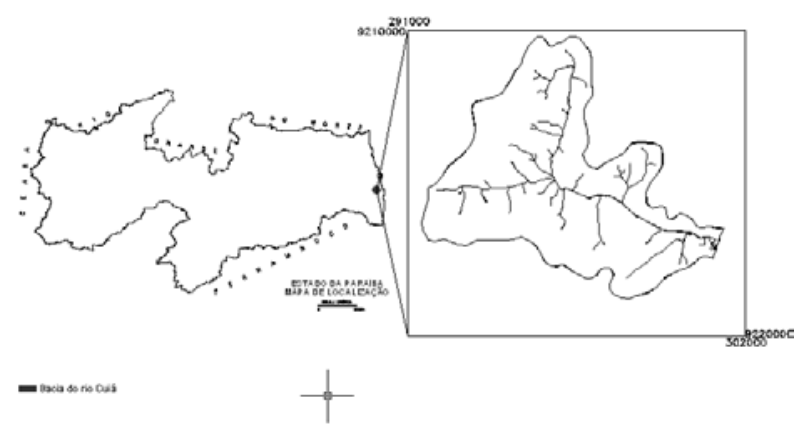

Figura 1 - L ocalização da bacia hidrográfica do rio Cuiá.
Mapeamento

Para gerar a base de dados temática, foi necessária a criação de um banco de dados no SPRING (Sistema de Processamento de Informações Georreferenciadas, do INPE) e um projeto para definir os limites geográficos da área em estudo, a projeção cartográfica do trabalho, o sistema de projeção. Para o projeto no SPRING, foi escolhido o sistema de projeção UTM, com datum horizontal em Córrego Alegre (origem no meridiano de $33^{\circ} 00^{\prime} 00^{\prime \prime}$ oeste de Grenwitch, o que equivale à zona 25).

Graus de I mpermeabilização

O mapa dos graus de impermeabilização foi produzido no SPRING utilizando a técnica de overlay, através do cruzamento entre os mapas de solo (pedológico), uso do solo e adensamento urbano, e tomando-se como base o processo de obtenção de classe segundo metodologia (Rocha, 2000). A distribuição em classes foi efetuada através da Equação (1) com base na amplitude entre os valores de coeficiente de impermeabilidade obtido na bacia através do overlay anteriormente citado, bem como o intervalo de cada classe, ou seja, maior valor encontrado $A_{M}$ subtraído do menor valor encontrado $A_{m} e$ dividido pelo número de classes.

$\pi=\frac{A_{M}-A_{m}}{5}$

onde $\pi$ é a faixa de grau de impermeabilização, e $A_{M}$ é a maior amplitude na classes e $A_{m}$ e menor amplitude na classes. Em seguida, o mapa numérico foi fatiado com as classes descritas na Tabela 1.

T abela 1 -Classes de graus de impermeabilização

\begin{tabular}{ll}
\hline Classificação Impermeabilização & Graus \\
\hline Muito Permeável & $0-4$ \\
Permeável & $4-8$ \\
Moderadamente Permeável & $8-12$ \\
Pouco Permeável & $12-16$ \\
Impermeável & $16-20$ \\
\hline
\end{tabular}

Com base nos mapas de solo, de uso do solo e de adensamento urbano, ponderados com seus respectivos graus de impermeabilização, pôde-se gerar um novo mapa utilizando as operações aritméticas do script LEGAL. 
Espacialização da Modelagem no SI G

A representação da produção de sedimentos em cada elemento plano discretizado da bacia do rio Cuiá, desenvolveu-se um Sistema de Informações Geográficas (SIG), utilizando o SPRING, que é um SIG no estado-da-arte com funções de processamento de imagens, análise espacial, modelagem numérica de terreno e consulta a bancos de dados espaciais. Silva et al. (2007) usaram esta técnica de mapeamento da erosão em ambiente SIG na bacia do riacho Guaraíra com o modelo hidrossedimentológico Kineros (Woolhiser, 1990), que pode ser usado tanto em bacias urbanas quanto em bacias rurais, pois possui diversos parâmetros físicos estimados tanto a partir do levantamento e medições em campo ou em laboratórios quanto pela literatura, ou otimizados como proposto por Santos et al. (2003). 0 modelo Kineros foi escolhido para o presente estudo por ser um modelo hidrossedimentológico cinemático, distribuído e de base física, cujos parâmetros de porosidade, condutividade hidráulica saturada, e potencial de capilaridade foram determinados com base nas características físicas dos solos de cada horizonte de solo para cada plano discretizado da bacia.

Infiltração do solo

O modelo Kineros possui um algoritmo de infiltração que permite uma aproximação física para a redistribuição da água no solo, incluindo a capacidade de recuperação de infiltração durante períodos de estiagens e determinando o percentual de infiltração depois deste período sem chuva. 0 modelo de infiltração descreve a capacidade de infiltração $f_{c}$ como uma função da profundidade infiltrada I, e necessita de quatro parâmetros básicos para descrever as propriedades de infiltração, que são: (a) condutividade hidráulica efetiva saturada do solo $\mathrm{K}_{\mathrm{s}}(\mathrm{m} / \mathrm{s})$; (b) capilaridade integral $\mathrm{G}(\mathrm{m})$; (c) porosidade $\phi$; e (d) índice de distribuição dos tamanhos dos poros $\lambda$. Há também um parâmetro opcional $C_{v}$, o qual descreve a variação aleatória no espaço das propriedades hidráulicas do solo, e uma variável relacionada ao evento denominada de saturação relativa inicial da camada superior do solo $S_{i}$, definida como $\theta_{i} / \phi$, na qual $\theta_{i}$ é a umidade inicial do solo.

0 modelo geral para a infiltrabilidade $f_{c}$ $(\mathrm{m} / \mathrm{s})$ é dado, como uma função da profundidade infiltrada I ( $m)$, por:

$$
f_{c}=K_{s}\left[1+\frac{\alpha}{e^{\alpha l / B}-1}\right]
$$

onde $B$ é $(G+h)\left(\theta_{s}-\theta_{i}\right)$, combinando os efeitos da franja capilar, $G(m)$, altura do escoamento $h(m)$, e a capacidade de armazenamento unitária $\Delta \theta=\left(\theta_{\mathrm{s}}-\right.$ $\theta_{\mathrm{i}}$ ), na qual $\theta_{\mathrm{s}}$ é a umidade de saturação do solo. 0 parâmetro $\alpha$ representa o tipo de solo; i.e, próximo de 0 para areia, neste caso a equação (2) se aproxima da equação de Green-Ampt; e $\alpha$ é próximo de 1 para um solo franco misto, em tal caso a equação (2) representa a equação de infiltração de SmithParlange. Como já mencionado, neste modelo existe uma redistribuição de água no solo, pois é considerado que existindo uma estiagem prolongada durante o evento de chuva o solo deve secar. 0 método de redistribuição e reinfiltração usado no modelo é descrito em Smith et al. (1993).

\section{Erosão nos planos e canais}

A equação geral usada para descrever a dinâmica dos sedimentos em qualquer ponto é dada pelo balanço de massa, similar ao escoamento cinemático da água nos planos:

$$
\frac{\partial\left(A C_{s}\right)}{\partial t}+\frac{\partial\left(Q C_{s}\right)}{\partial x}-e(x, t)=q_{s}(x, t)
$$

onde $C_{s}$ é a concentração de sedimentos $\left(\mathrm{m}^{3} / \mathrm{m}^{3} \not\right.$ é a vazão $\left(\mathrm{m}^{3} / \mathrm{s}\right), \mathrm{A}$ é a área da seção transversal do escoamento $\left(m^{2}\right), e(x, t)$ é a taxa de erosão do solo do leito $\left(\mathrm{m}^{2} / \mathrm{s}\right)$, eq é a taxa de entrada lateral de sedimentos nos canais $\left(\mathrm{m}^{2} / \mathrm{s}\right)$. Nos planos,e $\left.\mathrm{e}, \mathrm{t}, \mathrm{t}\right)$ é assumida como sendo composta de dois principais componentes, pela produção de solo erodido pelo impacto das gotas de chuva no solo descoberto, e pela erosão hidráulica (ou deposição) devido à interação entre a força de cisalhamento da água no solo solto do leito e a tendência das partículas do solo se sedimentarem sob a força da gravidade. Assim, a taxa total de erosão é um somatório da taxa de erosão pelo impacto das gotas de chuva es e a taxa de erosão hidráulica e:

$e=e_{s}+e_{h}$

A taxa de erosão pelo impacto da chuva é estimada como:

$$
e_{s}=c_{f} e^{-c_{b} h} r^{2}
$$


onde $r$ é a chuva efetiva $(\mathrm{m} / \mathrm{s})$, $c_{f}$ é uma constante relacionada ao solo e às propriedades da superfície, e $e^{-c_{h} h}$ é um fator que representa a redução na erosão causada pelo aumento da altura da água. 0 parâmetro $c_{n}$ representa a efetividade do molhamento da água superficial, assumido como sendo igual a 364,0. A taxa de erosão hidráulica (e é é estimada como sendo linearmente dependente da diferença entre a concentração de equilíbrio e a concentração corrente de sedimento, dada por:

$e_{b}=c_{g}\left(C_{m}-C_{s}\right) A$

onde $C_{m}$ é a concentração na capacidade de transporte em equilíbrio, $C_{s}=C_{s}(x, t)$ é a concentração de sedimento local corrente, e $c_{g}$ é um coeficiente de taxa de transferência $\left(s^{-1}\right)$, que é computado por:

$c_{g}=C_{0} \frac{v_{S}}{h}$ se $C_{s} \leq C_{m}$ (erosão) ou

$c_{g}=\frac{v_{S}}{h}$ se $C_{s}>C_{m}$ (deposição)

onde $C_{0}$ é o coeficiente de coesão do solo, e $v_{s}$ é a velocidade de queda da partícula $(\mathrm{m} / \mathrm{s})$. 0 modelo usa a relação da capacidade de transporte de Engelund e Hansen (1967), e a velocidade de queda da partícula é calculada pela seguinte equação:

$v_{s}^{2}=\frac{4}{3} \frac{g\left(\rho_{s}-1\right) d}{C_{D}}$

onde $g$ é a aceleração gravitacional $\left(\mathrm{m} / \mathrm{s}^{2}\right), \rho_{\mathrm{s}}$ é a densidade relativa do sedimento, igual a 2,65 , d é o diâmetro do sedimento $(\mathrm{m})$, e $C_{D}$ é coeficiente de resistência da partícula, que é uma função do número de Reynolds:

$C_{D}=\frac{24}{R_{n}}+\frac{3}{\sqrt{R_{n}}}+0,34$

sendo $R_{n}$ o número de Reynolds, dado por $R_{n}=$ $v_{s} \mathrm{~d} / \mathrm{v}$, onde $v$ é a viscosidade cinemática da água $\left(m^{2} / \mathrm{s}\right)$. As equações de erosão citadas são aplicadas para cada um dos cinco tamanhos de classes das partículas, que são usadas para descrever um solo quando existe uma variação do tamanho das mesmas. As equações (2-9) são resolvidas numericamente para cada espaço de tempo usado nas equações de escoamento, e para cada classe de tamanho de partícula. A Tabela 2 mostra um resumo dos valores dos parâmetros utilizados no presente estudo.
Tabela 2 - Parâmetros do Kineros para a bacia do Cuiá

\begin{tabular}{|c|c|c|}
\hline \multirow{2}{*}{ Parâmetros } & \multicolumn{2}{|c|}{ Camadas } \\
\hline & Superior & Inferior \\
\hline $\begin{array}{l}\text { Capilaridade média do solo, } \\
\text { G (mm) }\end{array}$ & $20-46$ & $12-23$ \\
\hline $\begin{array}{l}\text { Cond. hidr. saturada do solo, } \\
\mathrm{Ks}(\mathrm{mm} / \mathrm{h})\end{array}$ & $3-3,6$ & $0,5-0,8$ \\
\hline $\begin{array}{l}\text { Fração volumétrica de rocha, } R_{0} \\
\text { Porosidade, } \phi\end{array}$ & $\begin{array}{c}0,1-0,2 \\
0,15-0,45\end{array}$ & $\begin{array}{c}0,1-0,2 \\
0,13-0,25\end{array}$ \\
\hline $\begin{array}{l}\text { Espessura da camada superior, } \\
\text { H (mm) }\end{array}$ & $300-550$ & - \\
\hline Espaço da microtopografia, $S_{p}(m)$ & $0,1-0,3$ & - \\
\hline Altura da interceptação, $I_{n}(\mathrm{~mm})$ & $0,76-0,90$ & - \\
\hline Saturação inicial do solo, $\mathrm{S}_{\mathrm{i}}$ & $0,4-0,9$ & - \\
\hline Fração da cobertura vegetal, C & $1-2$ & - \\
\hline Coeficiente de Manning, $n$ & $0,06-0,08$ & - \\
\hline
\end{tabular}

Finalmente, os valores calculados da produção de sedimentos para todos os planos discretizados da bacia (período 1994-2004) foram inseridos no SIG, para a elaboração dos mapas anuais de produção de sedimentos para a bacia do rio Cuiá através do agrupamento de classes (produção de sedimentos) usando o Módulo de Agrupamento de Passo Igual e utilizando a seguinte equação:

$R_{v}=\frac{\mathrm{V}_{\text {máx }}-\mathrm{V}_{\text {min }}}{N_{g}}$

onde $R_{v}$ é a amplitude dos valores de cada grupo, $V_{\text {máx }}$ é o valor máximo do atributo, $V_{\text {min }}$ é o valor mínimo do atributo, e $\mathrm{N}_{\mathrm{g}}$ é o número de grupos.

\section{Áreas com riscos de inundação}

Inicialmente, foi realizado o reconhecimento no campo das áreas sujeitas à inundação (máxima cota atingida pela água), de acordo com o relato de moradores e ocorrências registradas na Defesa Civil. Esse reconhecimento possibilitou a delimitação de cota de inundação com o auxílio de um GPS e um altímetro, e, assim, foi gerada uma base de dados sobre as características hidrográficas do terreno com base nas cartas planialtimétricas do INTERPA (Instituto de Terras e Planejamento Agrícola da Paraíba) e nos pontos cotados com variação de centímetros obtidos junto a SEPLAN (Secretaria Planejamento, Desenvolvimento Urbano e Meio Ambiente) em levantamento topográfico. A digitalização das cartas foi realizada com o auxílio do SPRING, depois de receber uma preparação no IMPIMA que é um dos 
módulos de integração do SPRING. Com o IMPIMA foi possível a transformação da extensão TIFF ( $T$ agged Image File Format) para a extensão nativa do SPRING, o GRIB (Gridded Binary), um formato de valores de ponto de grade expresso no modo binário. Após esse processo, foram digitalizadas as curvas de nível e a rede de drenagem, e foram indicados os valores das curvas de nível com referências de $Z$ (altitude). Em seguida, foi gerada a grade retangular que é um modelo digital que aproxima superfícies através de um poliedro de faces retangulares.

Terminado o processo pelo qual foi gerada a grade retangular, foi criado um plano de informação cadastral contendo a representação vetorial dos rios e drenos existentes na bacia (Silva et al., 2006). Finalmente, foi construído um arquivo contendo as cotas de inundação com o nome de cada rio, a cota de inundação e a distância do ponto até a sua nascente, como mostra a Tabela 3.

Tabela $3-$ Rios e val ores das cotas encontradas

\begin{tabular}{lcc}
\hline NOME DO & $\begin{array}{c}\text { DISTÂNCIA DO } \\
\text { PONTO INICIAL } \\
\text { RIO }\end{array}$ & $\begin{array}{c}\text { VALOR } \\
\text { DE COTA } \\
(\mathrm{m})\end{array}$ \\
\hline CUIÁ & 0,00 & 3,90 \\
CUIÁ & 3905,00 & 5,00 \\
CUIÁ & 5315,00 & 7,70 \\
CUIÁ & 6245,00 & 7,70 \\
CUIÁ & 10500,00 & 10,20 \\
MANGABEIRA & 0,00 & 8,30 \\
MANGABEIRA & 513,00 & 9,70 \\
MANGABEIRA & 1449,00 & 10,10 \\
MANGABEIRA & 2299,00 & 10,30 \\
MANGABEIRA & 2901,00 & 9,80 \\
LARANJEIRA & 0,00 & 10,30 \\
LARANJEIRA & 689,00 & 10,20 \\
LARANJEIRA & 1087,00 & 10,00 \\
LARANJEIRA & 2321,00 & 10,10 \\
LARANJEIRA & 4928,00 & 9,90 \\
SONHAVA & 0,00 & 10,10 \\
SONHAVA & 314,00 & 9,70 \\
SONHAVA & 667,00 & 10,10 \\
SONHAVA & 920,00 & 9,90 \\
SONHAVA & 2217,00 & 9,50 \\
\hline
\end{tabular}

A partir dos níveis de água e da base cartográfica usada com equidistância das curvas de nível de 5 em 5 metros, foi possível gerar o mapa de inundação, com auxílio da ferramenta mancha de inundação baseado em funções do MIKE, disponível no SPRING.

\section{Deslizamento na bacia}

Para o estudo de deslizamento, utilizou-se a técnica de suporte a decisão AHP - Processo Analítico Hierárquico. Primeiramente, foram selecionados os temas que compõem os diferentes fatores contribuintes do processo de deslizamento (declividade, geologia, geomorfologia e uso do solo). Em seguida, foram escolhidos os critérios de comparação entre os diferentes temas e atribuídos os pesos de contribuição de cada tema para o processo de deslizamento, como mostrado na Tabela 4.

Tomando-se como base a técnica do AHP do SPRING, decidiu-se que na hierarquia que contribui para os desizamentos dos temas trabalhados, a declividade é mais importante que a geologia, seguindo pela geomorfolgia e do uso do solo. Assim indicando ao software que tema é mais importante que 0 outro.

T abela 4 - Critérios usados no suporte a decisão

\begin{tabular}{|c|c|c|c|}
\hline Critério 1 & & Peso & Critério 2 \\
\hline Declividade & 4 & $\begin{array}{c}\text { Moderada- } \\
\text { mente melhor }\end{array}$ & Geologia \\
\hline Declividade & 5 & Melhor & $\begin{array}{c}\text { Geomorfolo } \\
\text { gia }\end{array}$ \\
\hline Declividade & 5 & Melhor & U so do Solo \\
\hline Geologia & 2 & $\begin{array}{l}\text { Um pouco } \\
\text { melhor }\end{array}$ & $\begin{array}{l}\text { Geomorfolo- } \\
\text { gia }\end{array}$ \\
\hline Geologia & 3 & Algo melhor & U so do Solo \\
\hline $\begin{array}{l}\text { Geomorfolo- } \\
\text { gia }\end{array}$ & 2 & $\begin{array}{l}\text { Um pouco } \\
\text { melhor }\end{array}$ & Uso do Solo \\
\hline
\end{tabular}

Após selecionar os fatores que serão combinados e estabelecer a importância relativa de cada um deles, é possível obter através do SPRING uma indicação da consistência de seu julgamento. Para essa operação, a Razão de Consistência foi 0,036, e os pesos aplicados em cada um dos temas foram Declividade $=0,592$, Geologia $=0,205$, Geomorfologia $=0,123$, U so do Solo $=0,080$. Os desenvolvedores do SPRING aconselham que o índice de consistência seja sempre menor que 0,1 . Se o índice de consistência da análise for maior que 0,1 , considera-se a possibilidade de se refazer o julgamento, caso contrário o programa não realiza os cálculos de ponderação. Como resultado, esta função do SPRING gera uma estrutura de programa na linguagem LEGAL, que foi completado com as informações específicas sobre os dados nos quais se deseja aplicar o procedimento. 
U so adequado do solo na bacia

Para a construção do mapa síntese das variáveis encontradas no decorrer do trabalho, definiram-se cinco cenários de riscos para a bacia do rio Cuiá e realizou-se um cruzamento entres os temas. Esses cenários foram representados da seguinte forma: Cenário de risco muito alto $-R 5$, Cenário de risco alto $-\mathrm{R} 4$, Cenário de risco médio $-\mathrm{R} 3$, Cenário de risco baixo $-\mathrm{R} 2$ e Cenário sem risco $-\mathrm{R} 1$. Para o cruzamento, foi utilizada a expressão de comparação booleana envolvendo atributos espaciais como a operação "| | " OU tógico (união) e " $\& \&$ " E-lógico (intercessão).

No cenário R5 estão as áreas onde existe a maior suceptividade a deslizamento, sobreposta às áreas impermeáveis, com áreas de alta produção de sedimentos, ou seja, entre 2316,25 à 3088,34 ton/ ano $/ \mathrm{km}^{2}$.No cenário R4 estão as áreas onde existe um risco muito alto ao deslizamento, sobreposta às áreas pouco permeáveis, com áreas com produção de sedimentos entre 1544,17 à 2316,25 ton/ ano $/ \mathrm{km}^{2}$. O cenário R3 é representado pelas áreas onde existe alto risco ao deslizamento, sobrepostas às áreas moderadamente permeáveis, com áreas que produzem sedimentos entre 772,08 à 1544,17 ton/ ano/ km². O cenário R2 corresponde as áreas onde existe um risco moderado ao deslizamento, sobrepostas às áreas permeáveis, com áreas que produzem sedimentos entre 0,075 à 772,08 ton/ ano/ km². Já no cenário R 1 estão as áreas onde existe risco Nulo ou Baixo ao deslizamento, sobrepostas às áreas muito permeáveis, com áreas que tenham produção de sedimentos menores que 772,08 ton/ ano/ $\mathrm{km}^{2}$.

\section{RESULTADOS}

Graus de impermeabilidade do solo

A partir da metodologia descrita, obteve-se como resultado um mapa com os diferentes graus de impermeabilização do solo, com base na sobreposição (overlay) de três mapas: o do uso do solo, 0 de solo (pedológico) e o de adensamento urbano.

Baseado nos critérios estabelecidos (Tabela 1), foi possível construir um mapa da espacialização (Figura 2) do grau de impermeabilidade da bacia, segundo as cinco classes préestabelecidas: muito permeável, permeável, moderadamente permeável, pouco permeável e impermeável.

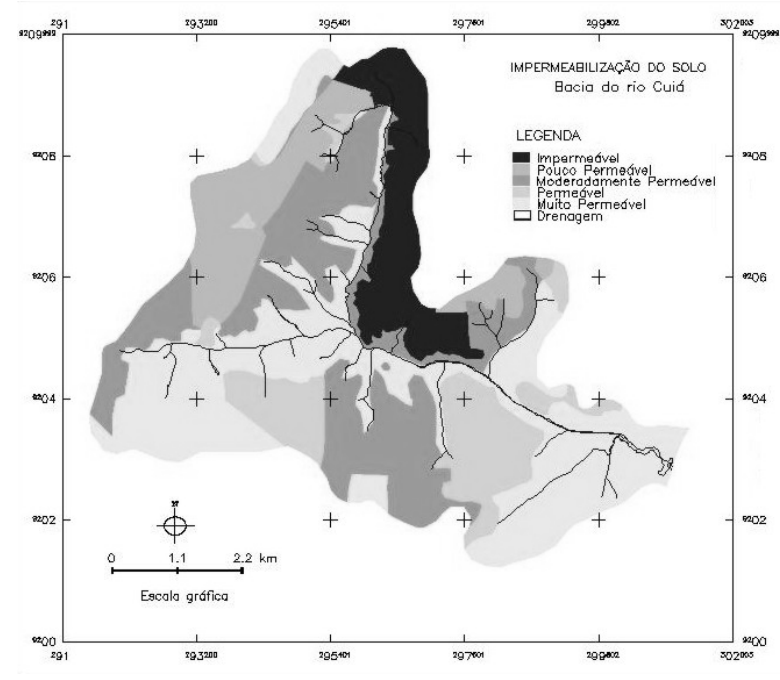

Figura 2 - Mapa de impermeabilização do solo da bacia do rio Cuiá.

A classe Muito Permeável foi obtida através da sobreposição de áreas onde a cobertura do solo não possuísse materiais que pudessem selá-to, como asfalto, concreto, grande superfícies de rochas expostas, e solos muito adensados de textura argilosa. Esta classe engloba áreas de vegetação natural e reflorestamento, ou seja, áreas sem cobertura impermeável, a qual totalizou $15,39 \mathrm{~km}^{2}$ da bacia. A classe Permeável é a sobreposição de áreas com baixa ocupação e com um nível baixo de adensamento ocupacional, como os loteamentos em fase inicial de instalação, e com cultura e pastagem, onde predominam as áreas permeáveis ( sem cobertura) com poucas edificações e com solos arenosos, totalizando uma área de $5,31 \mathrm{~km}^{2}$. A classe Moderadamente Permeável indica áreas mais adensadas e consolidadas com início de ocupação. Esta classe apresentou, em alguns casos, devido ao médio/ alto padrão de infraestrutura de algumas áreas, um grau de impermeabilização que pode estar mais estabilizado devido ao tipo do uso e tamanho das propriedades, com considerável presença de áreas verdes, arborização, praças e quintais. Esta classe ainda é composta de solos argiloarenosos, a qual dificulta a infiltração mesmo em áreas consideradas permeáveis pelo tipo de uso, e representa uma área de $10,38 \mathrm{~km}^{2}$. A classe Pouco Permeável descreve as áreas de uso predominantemente residencial, como novos conjuntos habitacionais com um menor número de ruas pavimentadas, onde 0 adensamento de construções é ainda maior em relação à classe Moderadamente Permeável, com a presença signifi- 
cativa de construções verticais de pequeno porte. A ocupação do solo tem padrão ordenado e ocupa uma área de $4,56 \mathrm{~km}^{2}$. A classe I mpermeável referese a áreas onde o adensamento urbano é alto e praticamente todos os espaços já foram edificados, com algumas poucas exceções. Estas áreas localizam-se, principalmente, na região mais central dos aglomerados urbanos do conjunto habitacional Mangabei$\mathrm{ra}$, sem presença de áreas arborizadas em alguns parques, tornando-se assim uma área praticamente impermeabilizada com áreas edificadas, ruas asfaltadas, com um padrão de ocupação variado, equipamentos institucionais, áreas comerciais e ainda contendo pequenos edifícios, totalizando uma área de $4,37 \mathrm{~km}^{2}$.

\section{Espacialização hidrossedimentológica}

A Figura 3 mostra a espacialização da produção de sedimentos para cada plano discretizado da bacia a partir da precipitação diária observada para o período compreendido de 1994-2004. De acordo com a representação espacial da estimativa da produção de sedimentos da bacia do rio Cuiá, segundo as classes de produção de sedimentos calculada através da modelagem hidrossedimentológica com o modelo físico Kineros e implantada no SIG, nota-se que mais de $90 \%$ da bacia apresenta alta susceptibilidade ao processo erosivo.

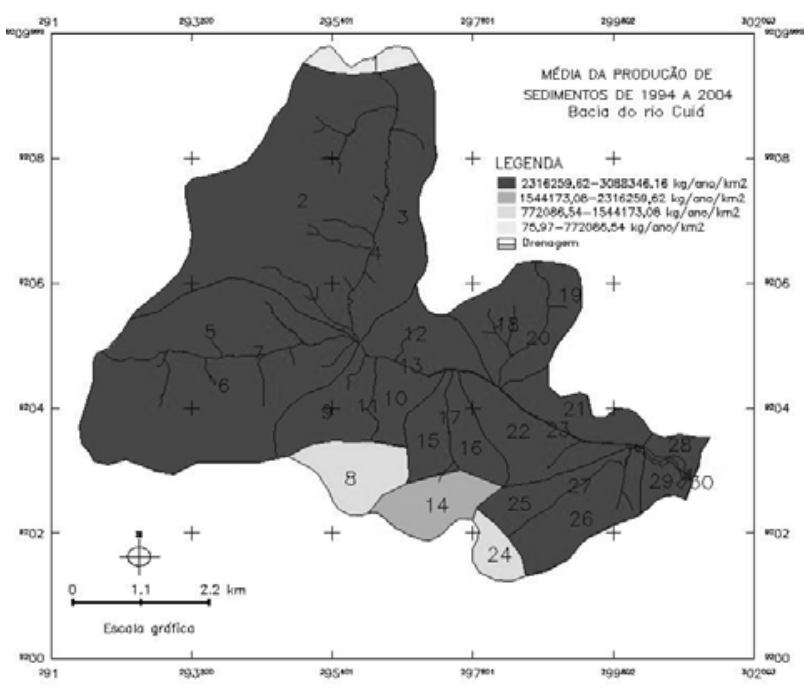

Figura 3 - Espacialização da produção de sedimentos de 1994 a 2004 na bacia do rio Cuiá.
Áreas com riscos de inundação

A partir dos níveis de água e da base cartográfica usada, com equidistância das curvas de nível de 5 em 5 metros, foi possível gerar o mapa de inundação com o auxílio da ferramenta para mancha de inundação baseada em funções do modelo hidrodinâmico MIKE que está disponível no SPRING. Com estes dados, foram obtidos os polígonos de inundação, com a base cartográfica citada anteriormente, para gerar o mapa com as áreas de inundação ( Figura 4).

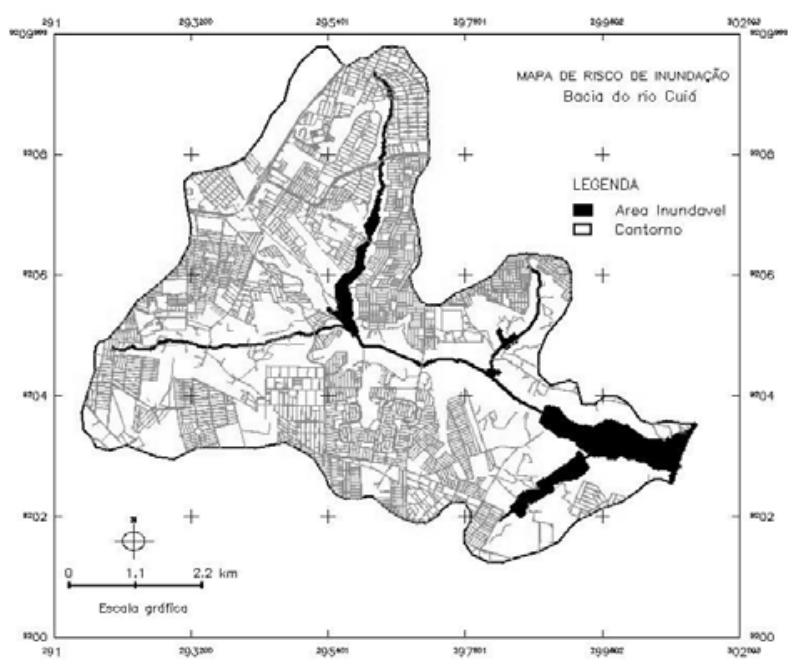

Figura 4 -Mapa das áreas com potencial de inundação da bacia do rio Cuiá.

A partir da análise realizada, verificou-se que os níveis das cotas de inundação ficam em torno de 3,90 a 10,20 m acima do nível do mar, com uma área de $1,56 \mathrm{~km}^{2}$, próxima a foz do rio Cuiá e localizada ao leste da bacia, nos bairros de Barra do Gramame e Costa do Sol, mais precisamente na Praia do Sol. 0 risco de inundação nesta área é maior para os moradores que residem próximo ao rio. No rio Sonhava, na parte nordeste da bacia do Cuiá, entre os bairros de Mangabeira e Costa do Sol, foi encontrada outra área com risco de inundação, atualmente observa-se que esta área ocorre uma grande ausência de ocupação, por se tratar de uma área de expansão urbana com uma pequena presença de vegetação. No rio Mangabeira, na parte sudeste da bacia, no bairro de Barra do Gramame, existe uma área de inundação, mas com o risco muito baixo pela ausência de ocupação e área essa ocupada com mangue e com culturas de subsistência nas partes de solos aluviais. 
As manchas de inundação, encontradas na parte norte da bacia, nos bairro de Mangabeira, José Américo, Jardim Cidade Universitária e Cidade dos Colibris, são as mais problemáticas por serem áreas com a maior taxa de adensamento urbano e onde existem aglomerados subnormais (favelas) registrados pela Defesa Civil já com registro de inundações, como é o caso de comunidades em Mangabeira e na Cidade dos Colibris. Apesar do diagnóstico preliminar apresentado neste estudo, algumas regiões estão aparentemente seguras em relação a inundações. Entretanto, é importante salientar que o acúmulo de lixo e à má drenagem superficial do terreno podem contribuir para o agravamento de problemas de inundação ao longo do tempo.

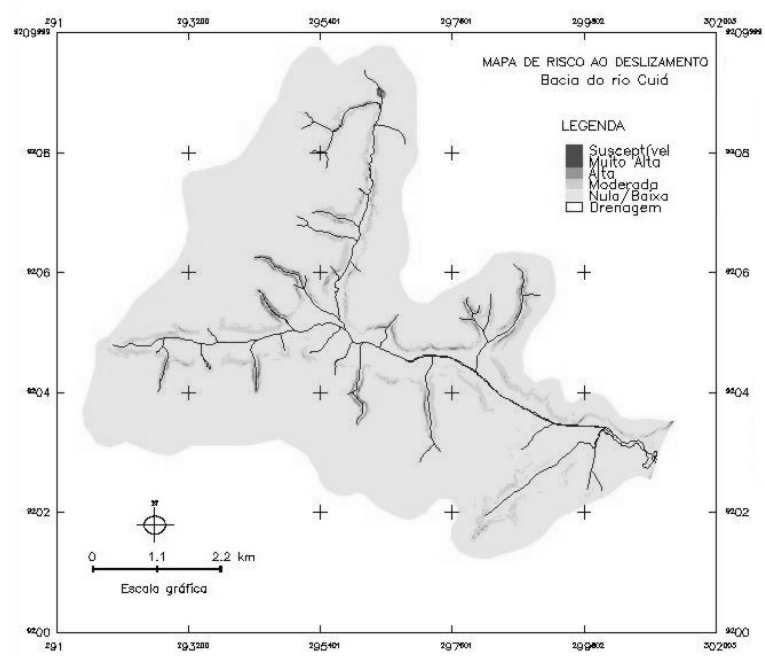

Figura 5 -Mapa de riscos de deslizamento na bacia do rio Cuiá.

\section{Riscos de deslizamento na bacia}

A avaliação ambiental efetuada através da análise do suporte à decisão permitiu a delimitação de diferentes setores com níveis de risco distintos, fruto das condições naturais e das formas de ocupação antrópica, mais ou menos impactantes, do meio físico, representadas por Cartogramas Digitais Classificatórios envolvendo Riscos e Potenciais (Declividade, Geologia, Relevo e U so do Solo). Os riscos de deslizamento são legendados segundo uma ordem hierárquica para as categorias ou classes: Nula ou Baixa, Moderada, Alta, Muito Alta e Susceptível (Augusto Filho, 2001). Foi encontrada na bacia do rio Cuiá uma área de $36,84 \mathrm{~km}^{2}$ com susceptibilidade nula/ baixa, onde o perigo de ocorrência de deslizamentos é praticamente inexistente; $2,70 \mathrm{~km}^{2}$ com áreas de Moderado risco, nessas áreas podem ocorrer deslizamentos por eventos chuvosos extremos, e chuvas prolongadas de intensidade moderada; $0,39 \mathrm{~km}^{2}$ com risco Alto de deslizamento, são áreas em encostas retilíneas com declive entre $16 \mathrm{e}$ $30 \% ; 0,04 \mathrm{~km}^{2}$ enquadrados na classe Muito Alta, com declividade maior que 30\%; e uma área de 0,01 $\mathrm{km}^{2}$ na classe Susceptível, cujas áreas possuem uma combinação de alta declividade, maior que $30 \%$, e encostas retilíneas (Figura 5).

\section{U so adequado do solo na bacia}

Com as análises e em conjunto com os cenários de riscos de inundação, deslizamento, erosão e impermeabilização. A Tabela 5 mostra um resumo do total de áreas ocupadas por cada cenário, e suas respectivas porcentagens.

Tabela 5 - Cenários de graus de riscos de inundação e erosão

\begin{tabular}{|l|c|c|}
\hline Cenário & Área $\left(\mathrm{km}^{2}\right)$ & Porcentagem $(\%)$ \\
\hline R1 & 30,24 & 75,64 \\
\hline R2 & 2,45 & 6,13 \\
\hline R3 & 1,44 & 3,61 \\
\hline R4 & 0,04 & 0,09 \\
\hline R5 & 5,81 & 14,54 \\
\hline Total & 40,00 & 100,00 \\
\hline
\end{tabular}

Conforme a proposta inicial da pesquisa elencou-se o uso adequado do solo levando em conta apenas as variáveis estudadas neste trabalho. 0 cenário R5 corresponde à área de recuperação urba$n a$, onde os problemas encontrados foram impermeabilização, erosão, inundação e deslizamento. A recuperação urbana sustenta-se em um retardamento no crescimento urbano nesta área através de leis, tendo em vista que essa área é a mais ocupada e adensada da bacia. 0 cenário R4 corresponde a uma área de recuperação ambiental, pois os problemas encontrados foram riscos de deslizamento e impermeabilização. Nesse cenário, a recuperação seria em forma de reflorestamento nas vertentes. 0 cenário R3 corresponde à área de reestruturação urbana, com riscos de deslizamento, erosão e impermeabilização. Esse cenário seria reestruturado por leis, pois é uma área ainda em grande crescimento urbano. 0 cenário R2 corresponde a uma área de conservação ambiental, pois o problema encontrado é o de deslizamento. Para esse cenário a preocupação seria conservar as áreas de encostas para evitar 0 agrava- 
mento dos poucos problemas e sua transformação em outro cenário. 0 cenário R1 corresponde à área de ocupação dirigida e com desenvolvimento econômico compatível, esse cenário seria destinado ao desenvolvimento de práticas de cultivos e ocupação urbana. Chegou-se a um mapa síntese dos riscos examinados na área de estudo (Figura 6). Este mapa pode ser denominado de U so Adequado com Base nos Riscos, ou poderia também ser chamando de Planejamento ou Zoneamento.

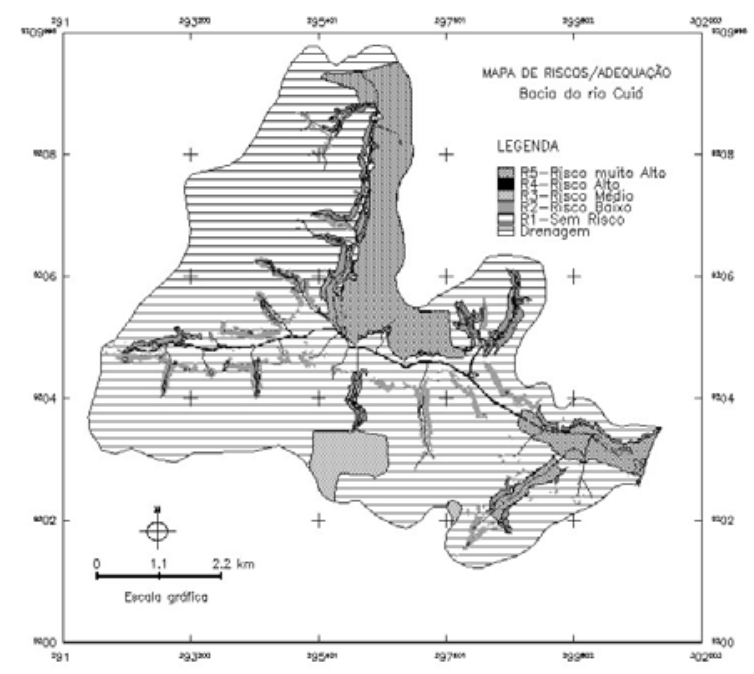

Figura 6 -Mapa com áreas de riscos e adequação da bacia do rio Cuiá.

\section{CONCLUSÃO}

Cerca de $10 \%$ de toda área da bacia do rio Cuiá pode ser enquadrada na classe que contém o solo com mais de $95 \%$ de impermeabilidade e se encontra exatamente no bairro de Mangabeira, que é o mais populoso de João Pessoa. Foi observado também que independentemente do ano analisado, as cabeceiras da bacia do rio Cuiá sempre apresentaram altos valores de produção de sedimentos. 0 aumento do escoamento superficial e a alta produção de sedimentos na bacia, que são transportados para os leitos dos rios, reduz a capacidade dos canais, provocando a inundação pelo transbordamento do mesmo. Observa-se que na maior parte da bacia não existe desizamento e que em apenas uma pequena parte da bacia, mais precisamente nas vertentes do rio Cuiá, existe o risco de ocorrer. Recomenda-se a manutenção de um plano de contingência com um conjunto de procedimentos e de ações para atender as emergências no período das chuvas, pois existem áreas críticas com um alto risco de deslizamento. Pela análise realizada no presente trabalho, recomenda-se que o cenário R5 seja considerado como sendo área de recuperação, onde os problemas encontrados foram de impermeabilização, erosão, inundação e deslizamento; o cenário R4 seja considerado como sendo uma área de recuperação ambiental, pois os problemas encontrados foram deslizamentos e impermeabilização; o cenário R3 como área de reestruturação urbana, com problemas de deslizamento, erosão e impermeabilização; o cenário R2 como sendo uma área de conservação ambiental, pois o problema encontrado é o de deslizamento; e finalmente, o cenário R 1 deve ser considerado como sendo área de ocupação dirigida e desenvolvimento econômico compatível. O SPRING se mostrou adequado para a realização destas tarefas, embora tenha sido instável às vezes, devido a constates travamentos, que levou a instalação de versões diferentes para a realização de determinadas funções.

\section{AGRADECIMENTOS}

Os autores agradecem a Defesa Civil do município de João Pessoa pelos dados sobre áreas de ricos, ao LEPAN pelo apoio com equipamentos, a Sergio Rosim (INPE) pelas discussões sobre os processos de macha de inundação e ao CT-Hidro/ MCT e CNPq pelo apoio financeiro através de bolsas aos autores.

\section{REFERÊNCIAS}

ARAÚJO, W. T. de.; SANTOS, R. L. \& LAGE, C. S. Análise do uso e ocupação do sítio urbano de Salvador/BA utilizando geoprocessamento. In: XXI Congresso Brasileiro de Cartografia, 2003, Belo Horizonte. Anais... Belo Horizonte, 2003.

AUGUSTO FILHO, O. Carta de risco de escorregamentos quantificada em ambiente de SIG como subsídio para implantação de seguros em áreas urbanas: um ensaio em Caraguatatuba (SP). 2001. 196p. Tese (Doutorado em Geociências e Meio Ambiente) - Instituto de Geociências e Ciências Exatas, Universidade Estadual Paulista. Rio Claro, 2001.

COSTA, H. B. Mapa de impermeabilização do solo da bacia do Ribeirão das Anhumas. Campinas-SP. In: XI Simpósio Brasileiro de Geografia Física Aplicada, 2005, 
São Paulo, Anais... São Paulo, 05 a 09 de Setembro de 2005.

CUNHA, S. B. da \& GUERRA, A. J. T. (org.). Geomorfologia e meio ambiente. Rio de Janeiro: Bertrand Brasil, 1999.

DELGADO, I. C. de M. S.; BATISTA, G. T. \& CATELANI, C. de S. O avanço da ocupação nas áreas de risco em Campos do Jordão: uma comparação entre 1986 e 2003. In: XII Simpósio Internacional em Percepción Remota y Sistemas de Información Geográfica, 2006, Cartagena de Indias, Anais... Cartagena de Indias, Colombia, Septiembre 24 al 29 de 2006.

ENGELUND, F. AND HANSEN, E. A Monograph on Sediment Transport in Alluvial Streams, Teknisk Forlag, Copenhagen, 62 pp., 1967.

ENOMOTO, C. F. Método para elaboração de mapas de inundação estudo de caso na bacia do rio Palmital. 2004. Dissertação (Mestrado em Engenharia de Recursos Hídricos e Ambientais), Setor de Tecnologia, Universidade Federal do Paraná. Curitiba, 2004.

GONÇALVES, L. F. H. \& GUERRA, A. J. T. Movimento de massa na cidade de Petrópolis (Rio de Janeiro). In: GUERRA, A. J. T. \& CUNHA, S. B. da (org.). Impactos Ambientais Urbanos no Brasil. Rio de Janeiro: Bertrand Brasil, 2001.

GONDIM FILHO, J. G. C.; et al. Projeto de gerenciamento integrado das atividades desenvolvidas em terra na bacia do São Francisco. Subprojeto 4.5C - Plano Decenal de Recursos Hídricos da Bacia Hidrográfica do Rio São Francisco-PBHSF (2004-2013). Versão 1.0. Estudo Técnico de Apoio ao PBHSF - No 10. ANA/GEF/PNUMA/OEA. Abril de 2004.

TUCCI, C. E. M.; SILVEIRA, A. L. L.; GOLDENFUM, J. A.; GERMANO, A. O. Inundações e drenagem urbana nos países da América do Sul, Brasil. In: TUCCI, Carlos Eduardo Morelli; BERTONI, Juan Carlos. (Org.). Inundações Urbanas na América do Sul. 1 ed. Porto Alegre: Editora da Universidade UFRGS, 2003, v. 1, p. 275-324.

ROCHA, C. H. B. Geoprocessamento Tecnologia Transdisciplinar. Juiz de Fora, MG; Ed. do Autor, 2000.

SANTOS, C. A. G.; SRINIVASAN, V.S.; SUZUKI, K.; WATANABE, M. Application of an optimization technique to a physically based erosion model. Hydrological Processes, Inglaterra, v. 17, n. 5, p. 989-1003, 2003.

SILVA, R. M.; SANTOS, C. A. G.; Silva, J. F. C. B. C. Evaluation of soil loss and land use in Guaraíra basin by remote sensing and runoff-erosion modeling. Journal of urban and environmental engineering, v. 2, p. 4452, 2007.

SILVA, L. P. e; PAIVA, F. M. de L; SILVA, R. M. da \& SANTOS, C. A. G. Predição hidrossedimentoológica numa bacia não-instrumentada através de modelagem e geoprocessamento. In: VII Encontro Nacional de
Engenharia de Sedimentos, 2006, Porto Alegre, Anais... Porto Alegre, Brasil, 20- 24 novembro ABRH, 2006.

SMITH, R.E., CORRADINI, C. AND MELONE, F. Modeling infiltration for multistorm runoff events. Water Resources Research, 29(1), 133-144, 1993.

VALÉRIO FILHO, M.; SERAFIM, C. R.; PEREIRA, M. N.; ALVES, M. Análise Temporal do Crescimento Urbano em Áreas de Risco à Erosão com o Suporte das Geotecnologias. In: XII Simpósio Brasileiro de Sensoriamento Remoto, 2005, Goiânia, Anais... Goiânia, Brasil, 16-21 abril 2005, INPE, p. 3927-3933

VIANNA, A. P. P. Utilização de modelagens hidrológica e hidráulica Associadas a um sistema de informações geográficas para mapeamento de áreas inundáveis Estudo de caso: município de Itajubá, MG. Dissertação de Mestrado, Belo Horizonte, 2000, MG.

VILLELA, S. M.; Mattos, A. Hidrologia Aplicada. São Paulo, McGraw-Hill, 1975.

WOOLHISER, D.A., SMITH, R.E. AND GOODRICH, D.C. KINEROS, A kinematic runoff and erosion model: Documentation and User Manual. U.S. Department of Agriculture, Agricultural Research Service, ARS77, 130 pp., 1990.

Spatial Analysis of Erosion and Flood Risks Within Cuiá River Basin

\section{ABSTRACT}

The present work aims to identify areas subject to flood, landslide and soil erosion within Cuiá river basin using GIS and runoff-erosion modeling. The flood, sediment yield, impermeabilization and landslide maps were integrated to obtain an adequate soil use map. A synthesis map with the variable found was obtained, which provided five different scenarios according to the degree of risk. The relationship between the subjects was cross-matched using Boolean logic, i.e., union and intersection. A total of $30.24 \mathrm{~km}^{2}$, which is $75.64 \%$ of the basin, was associated with the R 1 scenario (without risk). Thus, a large part of the basin is not in risk areas. The proposal for soil use and adequation suggested in this work based on the following variables (a) flood and landslide risks, (b) degree of impermeabilization, and (c) erosion, recommen ds that the R5 scenario be designated as an urban recovery area, since it presents impermeabilization, erosion, flood and landslide problems; that the $\mathrm{R} 4$ scenario be an environmental recovery area, as it is subject to risk of landslide and a high degree of impermeabilization; the R3 scenario could be an urban restructuring area, due to the problems of landslide, 
erosion and impermeabilization; the $\mathrm{R} 2$ scenario could be an environmental conservation area, since there the only problem is landslides, and finally the R1 scenario could be an area for oriented occupation and for compatible economic development, sinceit does not present any risk.

Key-words: M odeling, landslide, GIS, watershed 